A. BAMERI ${ }^{1}$, Researcher, Master of Science

M. CHERAGHI SEIFABAD ${ }^{1}$, Associate Professor, Doctor of Philosophy

S. H. HOSEINIE ${ }^{1}$, Assistant Professor and Head of Laboratory, Doctor of Philosophy, hadi.hoseinie@iut.ac.ir

${ }^{1}$ Department of Mining Engineering, Isfahan University of Technology, Isfahan, Iran

\title{
UNCERTAINTY CONSIDERATION IN ROCK MASS BLASTABILITY ASSESSMENT IN OPEN PIT MINES USING MONTE CARLO SIMULATION
}

\section{Introduction}

Blasting is one of the most important unit operations in surface mines. The cost of blasting can be $25 \%$ of the mineral production costs [1]. The quality of blasting results affects the efficiency of loading, hauling, crushing, and processing operations, which influence the energy consumption and environmental impacts of mining [2, 3]. Fragmentation as a direct measure of blasting quality is affected by many parameters which are mainly divided into two categories [4-7]:

a) Controllable parameters such as the explosive type and blasting pattern geometry

b) Uncontrollable parameters such as rock mass condition and geological structures

Uncontrollable parameters are known as the most important influencing variables in the blasting outcomes [8, 9]. The selection of the right controllable blasting parameters, especially pattern geometry, is carried out based on rock mass characteristics. Hence, it affects the workability of fragmented rocks in the rest of the production process such as crushability and grindability [10] and could clearly control the unwanted side effects of blasting such as flyrock [11], ground vibrations, and airblast [12].

Blastability is the measure of rock mass resistance to dynamic loading of blasting and fragmentation stress [13]. It is challenging to assess the blastability accurately due to the large scale effects of the blast, the complexity of rock mass structures, and the simultaneous variation of all associated rock mass factors [14]. Thus, so far many researchers have tried to summarize the rock mass blastability in index measures or classifications such as Blastability Index (BI) [15], Energy-Block Transition (EBT) model [16], Blastability Quality System (BQS) [17, 18], neural networks [19], fuzzy sets [20] and Rock Mass index (RMi) [21]. As the review of past literature reveals, the $\mathrm{BI}$ presents a basic definition of blastability and is the most popular approach for the blastability analysis. The main reason for this fact is the easiness of application and reasonable outputs. However, there are some problems in the scoring of $\mathrm{BI}$ parameters in the field, which will be discussed in the following parts.
Considering the variable nature of input parameters in all mentioned methods, the blastability analysis includes inherent uncertainties which could affect the blasting results significantly [22]. When a fixed score is rated to an input parameter of blastability classification methods, it could misaddress the engineers in other rock masses and make unrealistic overview and judgments because of the high level of undetectable variation in rock mass characteristics. Sometimes the combination of simultaneous changes in input parameters is not captured in the field studies and observations. One of the applicable approaches to overcome the influence of unobserved rock mass characteristics and existent uncertainties is simulation, particularly the Monte Carlo method. In this approach, all considered input parameters are taking into account as statistical distribution functions instead of fixed values. This could widely provide a better view of output parameters while presents it as a distribution function too.

In this research, a Monte Carlo simulation program has been developed to assess the rock mass blastability in open pit mines using a stochastic modeling approach, based on the Blastability Index (BI). A wide range of field data has been collected from Sungun copper mine to develop the 
Table 1. Ratings for blastability index parameters [15]

\begin{tabular}{|c|c|}
\hline Score & Parameters \\
\hline \multicolumn{2}{|c|}{ Rock Mass Description } \\
\hline 10 & Powdery/friable \\
\hline 20 & Blocky \\
\hline 50 & Totally massive \\
\hline \multicolumn{2}{|c|}{ Joint Plane Spacing } \\
\hline 10 & Close $(<0.1 \mathrm{~m})$ \\
\hline 20 & Intermediate $(0.1-1)$ \\
\hline 50 & Wide \\
\hline \multicolumn{2}{|c|}{ Joint Plane Orientation } \\
\hline 10 & Horizontal \\
\hline 20 & Dip out of face \\
\hline 30 & Strike normal to face \\
\hline 40 & Dip into face \\
\hline $10-50$ & Specific Gravity Influence \\
\hline $1-10$ & Hardness \\
\hline
\end{tabular}

probabilistic structure of rock mass blastability assessment. In the following parts of the paper, the detailed information about data collection, simulation process, and research outputs are presented.

\section{Blastability Index (BI)}

$\mathrm{BI}$ was introduced by Lily [15] based on the in-situ characteristics of the rock mass to predict specific charge of blasting in open pit mines. It is also applied for the description of the effortlessness of blasting and rock fragmentation. The $\mathrm{BI}$ is calculated by equation (1), which is supported by parameters presented in Table 1

$\mathrm{BI}=0.5(\mathrm{RMD}+\mathrm{JPS}+\mathrm{JPO}+\mathrm{SGI}+\mathrm{H})$.

The maximum amount of $\mathrm{BI}$ is 100 , and the higher $\mathrm{BI}$ means more satisfaction from blasting results. Based on calculated $\mathrm{BI}$ value, the rock mass blastability is described as "very difficult" (BI $<8)$, "difficult" $(8<\mathrm{BI}<13)$, "moderate" $(13<\mathrm{BI}<20)$, "easy" $(20<\mathrm{BI}<40)$ and "very easy" $(40<\mathrm{BI})$ [23]. This difference in description has apparent effects on excavation cost.

\section{Case study, Sungun Copper Mine \\ Data collection}

In this paper, a case study was carried out in Sungun copper mine in north-west of Iran, to collect the required data for simulation. The annual production of this mine is around 14 million tones. The ore body of the mine has grade variation due to its porphyry and massive shape. Generally, it consists of two types of low-grade and high-grade minerals, which are surrounded by waste and interlocking dike masses. In the pit area, 80 faults are active in small to medium size and affect the rock masses' characteristics significantly. In total, the mentioned $\mathrm{BI}$ parameters were measured and collected in 46 points (mainly in ore rock

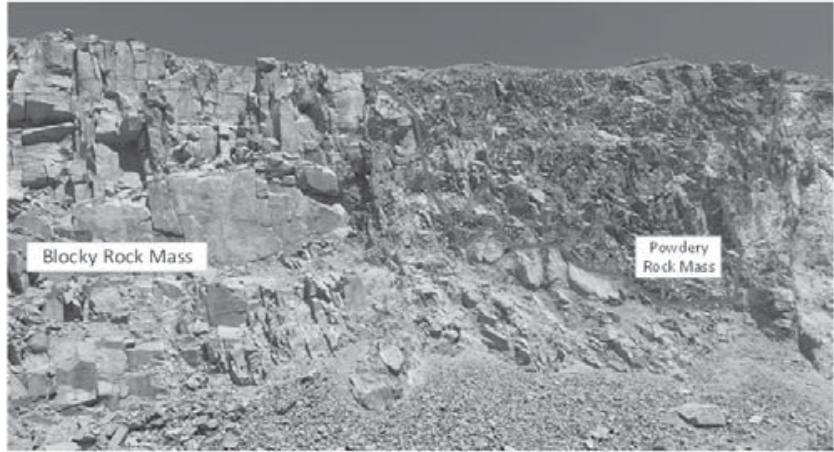

Fig. 1. Mixed-face condition in studied rock masses in Sungun Copper Mine

masses) of the pit walls. For each data collection point, a window of bench face with the dimensions of 8 meters length and 12.5 meters height (equal to mine bench height) were considered to be able to map the rock mass conditions (specially RMD) with accurate and acceptable level. As it is seen, the $\mathrm{BI}$ classification is based on the qualitative evaluation of rock mass condition, which is mixed with some quantitative measurements. Therefore, assigning a fixed value to a specific rock mass could raise uncertainty in overall blastability assessment. For instance, when the rock mass is mixed with all three RMD conditions, the scoring faces difficulty, and

Table 2. Results of BI parameters collected from case study mine

\begin{tabular}{|c|c|c|c|c|c|c|c|c|c|c|c|}
\hline \multirow{2}{*}{$\begin{array}{l}\text { Site } \\
\text { No. }\end{array}$} & \multicolumn{5}{|c|}{ Parameters' Scores } & \multirow{2}{*}{$\begin{array}{l}\text { Site } \\
\text { No. }\end{array}$} & \multicolumn{5}{|c|}{ Parameters' Scores } \\
\hline & RMD & JPS & JPO & SGI & $\mathrm{H}$ & & RMD & JPS & JPO & SGI & $\mathrm{H}$ \\
\hline 1 & 20 & 0.55 & 22 & 17.75 & 4 & 24 & 15 & 0.24 & 25 & 16.25 & 4.5 \\
\hline 2 & 20 & 0.55 & 25 & 14.25 & 3 & 25 & 17 & 0.27 & 25 & 10 & 6 \\
\hline 3 & 20 & 0.55 & 27 & 20 & 3.5 & 26 & 18 & 0.24 & 23 & 15.5 & 5 \\
\hline 4 & 20 & 0.55 & 18 & 16 & 3.5 & 27 & 18 & 0.25 & 21 & 11.25 & 4.5 \\
\hline 5 & 8 & 0.2 & 25 & 13.75 & 4 & 28 & 20 & 0.37 & 25 & 11.5 & 4.5 \\
\hline 6 & 20 & 0.35 & 27 & 15.25 & 5 & 29 & 16 & 0.15 & 25 & 12.75 & 5.5 \\
\hline 7 & 18 & 0.12 & 25 & 11.75 & 4.5 & 30 & 15 & 0.14 & 25 & 10 & 5.5 \\
\hline 8 & 20 & 0.55 & 25 & 10 & 4 & 31 & 20 & 0.15 & 25 & 14.75 & 4 \\
\hline 9 & 20 & 0.22 & 25 & 10 & 3.5 & 32 & 20 & 0.1 & 25 & 10 & 5.5 \\
\hline 10 & 15 & 0.25 & 28 & 10 & 6 & 33 & 20 & 0.1 & 25 & 32 & 4 \\
\hline 11 & 14 & 0.175 & 25 & 10 & 6 & 34 & 17 & 0.16 & 27 & 13.25 & 5 \\
\hline 12 & 12 & 0.08 & 25 & 10 & 6 & 35 & 15 & 0.12 & 27 & 25.75 & 6 \\
\hline 13 & 20 & 0.3 & 25 & 18.25 & 6 & 36 & 13 & 0.07 & 25 & 22.5 & 3.5 \\
\hline 14 & 15 & 0.32 & 33 & 10 & 4 & 37 & 20 & 0.3 & 25 & 19.25 & 4 \\
\hline 15 & 13 & 0.09 & 25 & 10.75 & 5 & 38 & 20 & 0.27 & 23 & 24 & 3 \\
\hline 16 & 10 & 0.06 & 25 & 10.75 & 5 & 39 & 20 & 0.25 & 27 & 20 & 5 \\
\hline 17 & 15 & 0.32 & 23 & 10 & 4 & 40 & 20 & 0.25 & 25 & 11.5 & 4.5 \\
\hline 18 & 15 & 0.15 & 30 & 10 & 3 & 41 & 12 & 0.09 & 25 & 19 & 4 \\
\hline 19 & 15 & 0.15 & 25 & 10 & 4 & 42 & 17 & 0.16 & 25 & 20 & 4.5 \\
\hline 20 & 20 & 0.25 & 25 & 21.5 & 5.5 & 43 & 20 & 0.21 & 27 & 10 & 5.5 \\
\hline 21 & 20 & 0.55 & 25 & 21.25 & 3 & 44 & 20 & 0.27 & 22 & 10 & 4.5 \\
\hline 22 & 20 & 0.35 & 25 & 20.25 & 5.5 & 45 & 20 & 0.27 & 27 & 10 & 3.5 \\
\hline 23 & 17 & 0.175 & 15 & 22.5 & 5.5 & 46 & 15 & 0.17 & 25 & 10 & 5.5 \\
\hline
\end{tabular}


Table 3. The results of the statistical analysis of rock mass blastability parameters

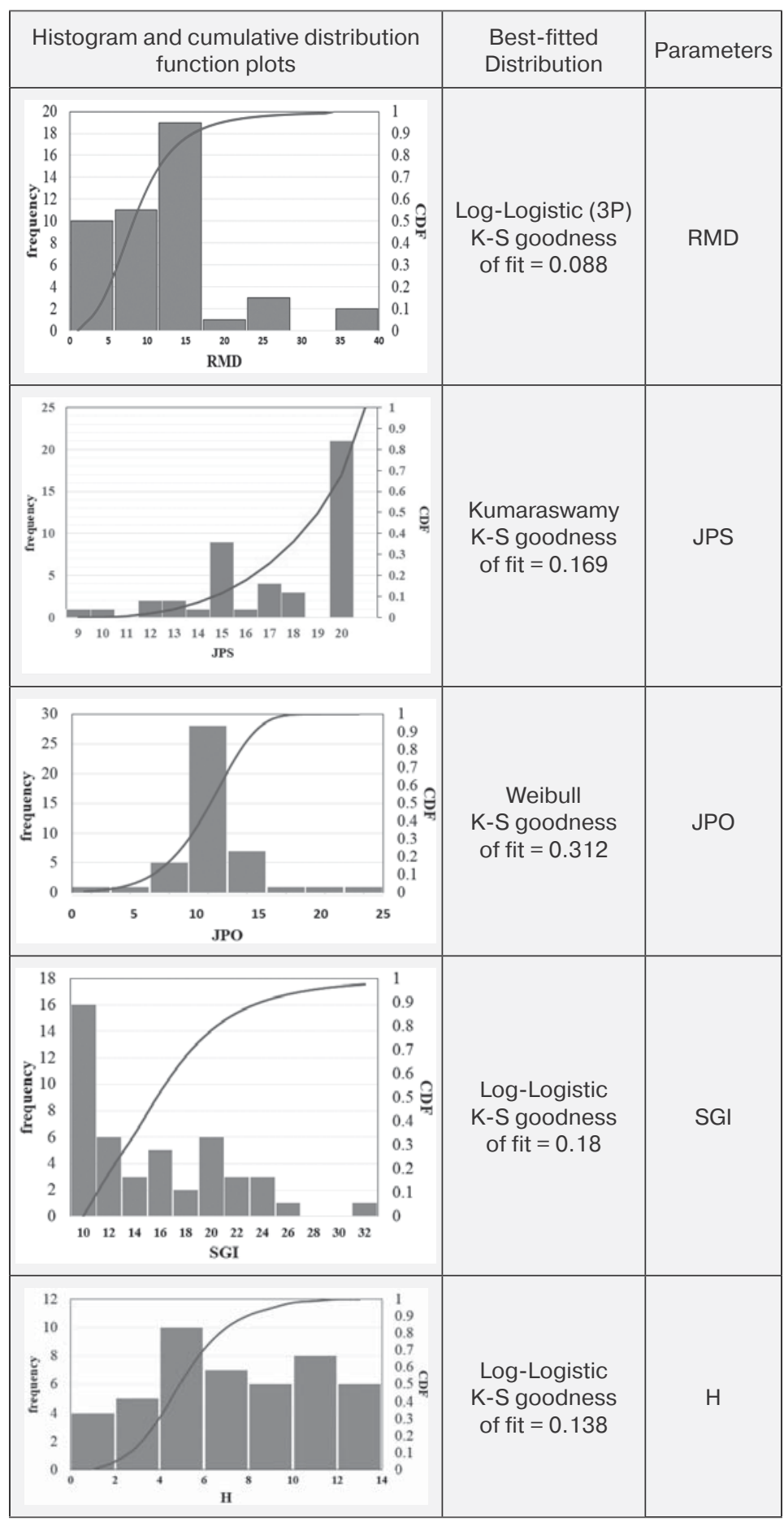

\section{Statistical analysis}

As an essential requirement for the Monte Carlo simulation, it is essential to analyze the collected geotechnical data statistically. For this purpose, all available data were applied to find out the bestfitted distribution for each mentioned parameter. Generally, 55 different distributions, especially the most applicable ones such as Weibull (two and three parameters), exponential, normal, lognormal, logistic, log-logistic, and Gamma, were tested on the data using Easyfit software. The Kolmogorov-Smirnov (K-S) goodness-of-fit test was considered for the selection of best-fitted distributions. The results of the statistical analysis are presented in Table 3.

\section{Monte Carlo Simulation}

Monte Carlo is a simulation technique applied for understanding the effects of uncertainty in forecasting and engineering measurements and provides an estimation of an unknown value. This method was first proposed by Metropolis and Ulam [24]. Johansen and Evers [25] believe that the most formal definition of this method has been presented by Halton [26] as "representing the solution of a problem as a parameter of a hypothetical population, and using a random sequence of numbers to construct a sample of the population, from which statistical estimates of the parameter can be obtained." It is a stochastic method that is performed upon numerical values of parameters that are randomly selected from statistical distribution functions utilizing the randomnumber-generator functions within [0-1] interval. The simulation is repeated $n$ times, each time using different randomly-selected values, and the resulted outputs are a large number of results from the model, which are summarized and described in the form of statistical distribution as well. In this paper, a MATLAB code was developed for simulation running. The reliable and comprehensive toolbars, predefined random generator functions, and being user friendly are three main reasons for using the MATLAB instead of other programming languages or commercial simulation software.

Finally, by running the simulation with the iteration number of 2000 , the values of BI were calculated by the program. Fig. 2 shows the results of simulation and histogram of field-collected $\mathrm{BI}$ values. As seen in this figure, the blastability condition of less than two percent of the rock masses is very difficult $(\mathrm{Bl}<8)$, the others are difficult, moderate, easy and very easy conditions with the share of $8,47.5,37.5$ and 5 percent respectively. Average blastability of rock masses in the studied mine is 18

the user should make the judgment and put a score considering all conditions by himself. One of the easiest ways to overcome this challenge is by applying a weighted mean of scores, which is used in this research too. Fig. 1 presents the mixed-face condition of mine benches, which has been observed during the field studies, and the BI of the two different types of rock masses were combined using areabased weighed mean. Table 1 presents the collected data from all 46 mentioned points of the mine in detail. which is close to moderate score of blastability classification as well. In comparison the actual blastability values with the results of simulation, it is obvious that these values vary from 32 to 54 . It shows that the average blastability score is 40 and the overall blastability is in easy condition. The difference between these two results obviously reveals that how much uncertainty is associated with blastability analysis because of lack of enough data and wide range of variation in input parameters. 


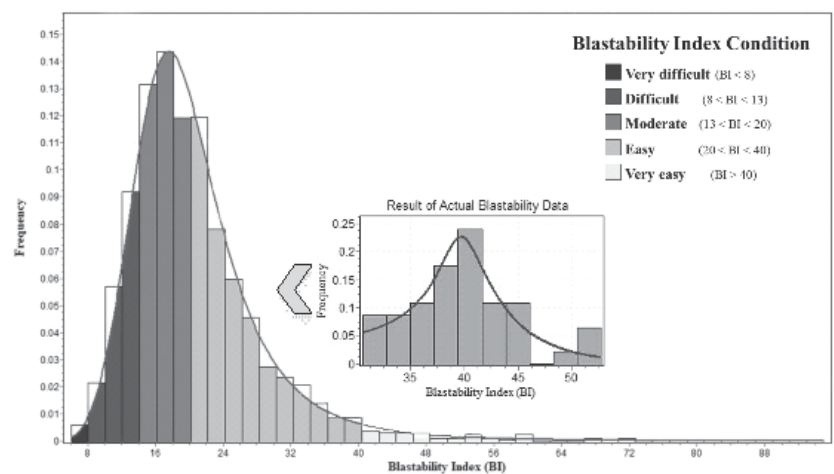

Fig. 2. Results of simulation and cooperation with real fieldcollected data

\section{Conclusion}

In modern blasting in open pit mines, it is confirmed that rock mass characteristics play a crucial role in controlling the blasting results. Accurate blastability assessment of rock masses not only enhances the quality of fragmentation but also decreases the production costs significantly. The main challenge in the optimal design of blasting patterns is the geological uncertainties which directly deviates the blasting from its primary production goals.

This paper presents a stochastic analysis of rock mass blastability in open pit mines. At the same time, the lake of data and cost restrictions does not allow in-depth and comprehensive field studies. Monte Carlo simulation, as a powerful tool for uncertainty mapping in any multi-variable measurements, has been applied for blastability assessment of rock masses. The overall results of simulation reveal that the Monte Carlo method could provide a better estimate of any possible combination of geological factors (2000 conditions in developed simulation program). Considering the achievements, if the blasting designers rely on just limited knowledge of field studies, it could lead them to inefficient blasting with uncontrollable side effects. As the field observations of the authors show, unexpected results of blasting in Sungun mine is clear evidence of uncertainty in blastability assessment of rock mass and its effects on unwanted side effects and oversize formation by inefficient blasting (Fig. 3).

The comparison between real field data and simulated distribution function of $\mathrm{BI}$ values reveals that simulation provides a broader range of rock mass conditions and can separate the boundary condition of rock mass in a better way. Therefore, it is recommended to apply the Monte Carlo simulation method to forecast any possible conditions and to reduce the uncertainty before any pattern design and blasting optimization.

References

1. Menzhulin M. G., Khoreva A. Y. Afanasiev P. I., Tyulkin S. A. Drilling and blasting parameters for Gavrilovo granite deposit, Gornyi Zhurnal. 2017. No. 1, pp. 42-46. DOI: 10.17580/ gzh.2017.01.08

2. Taherkhani H., Doostmohammadi R. Transportation costs: a tool for evaluating the effect of rock mass mechanical parameters on blasting results in open pit mining. Journal of Mining Science. 2015. Vol. 51. pp. 730-742.

3. Kazakov N. N. The destruction and crushing of rocks in open cast mine. Explosion Technology. 2017. Vol. 118/75. pp. 5-19.
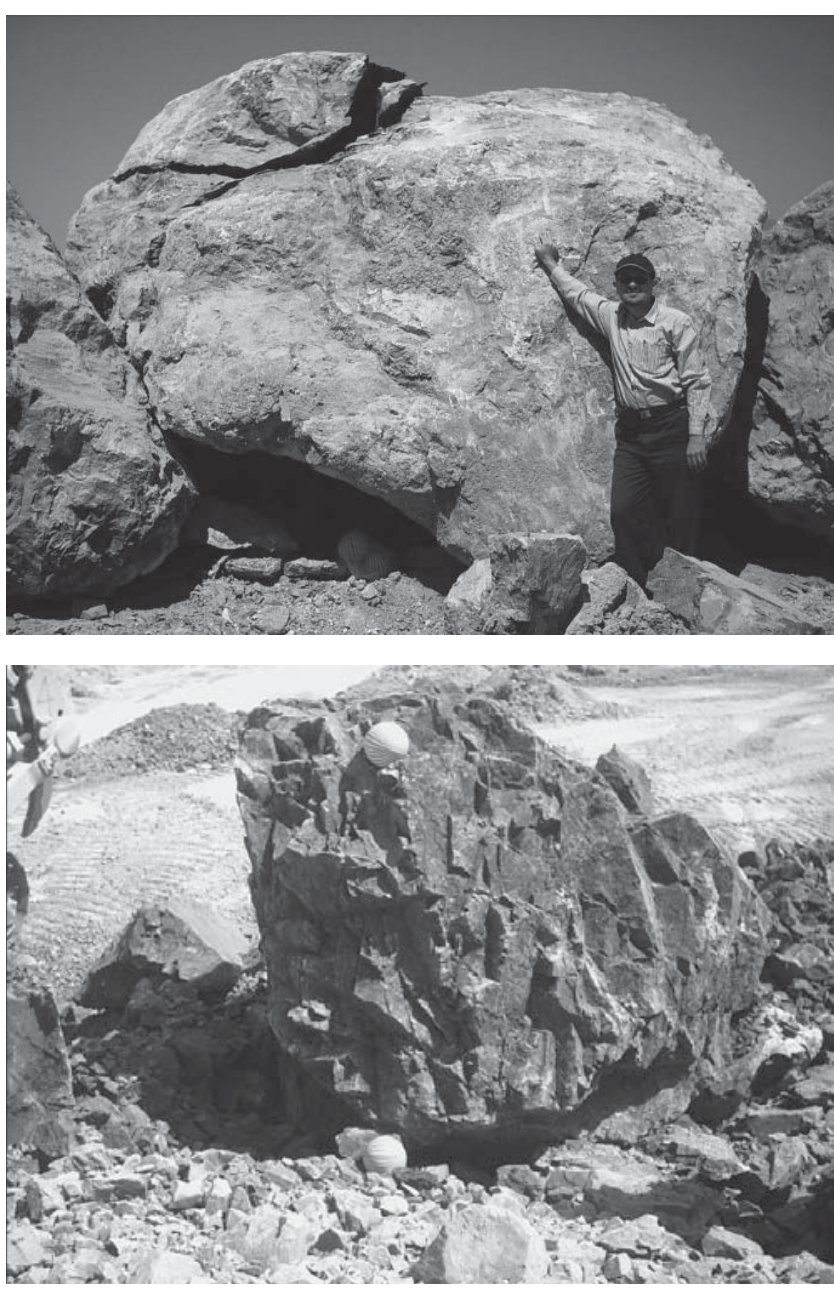

Fig. 3. Effects of uncertainty on oversize block formation and inefficient blasting results in Sungun Copper Mine (in the right photo the diameter of green plastic balls are $17 \mathrm{~cm}$ )

4. Singh D., Sastry. V. Influence of structural discontinuity on rock fragmentation by blasting. Proceedings of the 6th International Symposium on Intense Dynamic Loading and its Effects. Beijing, China, June 3-7 1986.

5. Ghosh A., Daemen J., Van Zyl D. Fractal-based approach to determine the effect of discontinuities on blast fragmentation. The 31st U.S Symposium on Rock Mechanics (USRMS). Golden, Colorado, USA, 18-20 June 1990.

6. Mehrdanesh A., Monjezi M., Sayadi A. R. Evaluation of the effect of rock mass properties on fragmentation using robust techniques. Engineering with Computers. 2018. Vol. 34(2). pp. 253-260.

7. Akbari M., Lashkaripour Gh., Yarahamdi Bafghi A., Ghafoori M. Blastability evaluation for rock mass fragmentation in Iran central iron ore mines. International Journal of Mining Science and Technology, 2015. Vol. 25(1). pp. 59-66.

8. Tyupin V. N., Anisimov V. N. Effect of Geological and Geophysical Characteristics of Complex-Structure Ferruginous Quartzite Ore Bodies on Blasting and Processing Performance. Journal of Mining Science. 2018. No. 54. pp. 48-52. 
9. Viktorov S. D., Kazakov N. N., Shlyapin A.V. Crushing rock between two charges and at an extreme charge in the top layer of the opencast bench. Explosion Technology. 2017. Vol. 118/75. pp.18-30.

10. Khademian A., Bagherpour R. Alteration of grindability of minerals due to applying different explosives in blasting operation. Minerals Engineering. 2017. Vol. 111. pp. 174-181.

11. Ghasemi E., Sari M., Ataei M. Development of an empirical model for predicting the effects of controllable blasting parameters on flyrock distance in surface mines. International Journal of Rock Mechanics and Mining Sciences. 2012. Vol. 52. pp. 163-170.

12. Morin M. A., Ficarazzo F. Monte Carlo simulation as a tool to predict blasting fragmentation based on the Kuz-Ram model. Computers \& Geosciences. 2006. Vol. 32(3). pp. 352-359.

13. Xiao S., Li K., Ding X., Liu T. Rock mass blastability classification using fuzzy pattern recognition and the combination weight method. Mathematical Problems in Engineering. 2015. Article 724619 .

14. Viktorov S. D., Zakalinsky V. M., Osokin A. A. Theoretical background of large-scale and selective blasting effect on rocks in complex ground conditions. Journal of Mining Science. 2014. Vol. 50. pp.1040-1046.

15. Lilly P. An empirical method of assessing rock mass blastability. Proceeding of Large Open Pit Mining Conference. Melborn, Australia, 1986. pp. 89-92.

16. Latham J. P., Lu P. Development of an assessment system for the blastability of rock masses. International Journal of Rock Mechanics and Mining Sciences. 1999. Vol. 36(1). pp. 41-55.

17. Chatziangelou M., Christaras B. Blastability Index on Poor Quality Rock Mass. International Journal of Civil Engineering (IJCE), 2013. Vol. 2(5). pp. 9-16.

18. Chatziangelou M., Christaras B. A. New Development of BQS (Blastability Quality System) for Closely Spaced Formations. Journal of Geological Resource and Engineering, 2017. Vol. 1. pp. 24-37.
19. Feng X. A neural network approach to comprehensive classification of rock stability, blastability and drillability. Internationa Journal of Surface Mining and Reclamation. 1995. Vol. 9(2). pp. 57-62.

20. Azimi Y., Osanloo M., Aakbarpour-Shirazi M., Aghajani Bazzazi A. Prediction of the blastability designation of rock masses using fuzzy sets. International Journal of Rock Mechanics and Mining Sciences. 2010. Vol. 47(7). pp. 1126-1140.

21. Hoseinie S. H., Pourrahimian Y., Fardin N., Aghababaei H. Determination of blasting Index (BI) to predict the fragmentation amount and blasting efficiency of Sungun copper mine using Rock Mass index(RMi). 8th International Conference on Rock Fragmentation by Blasting (Fragblast-8). Santiago, Chile. May 7-11 2006. pp. 321-325.

22. Norov Y. D., Bunin Z. V., Nutfullaev G. S., Zairov Sh. Sh. Intensification of blasting of different quality rock masses using explosive charges with cumulative effect. Gornyi Zhurnal. 2016. No. 2. pp. 16-20. DOI: 10.17580/gzh.2016.02.03

23. Chatziangelou M., Christaras B. A Geological Classification of Rock Mass Quality and Blast Ability for Widely Spaced Formations. Journal of Geological Resource and Engineering. 2016. Vol. 4. pp. $160-174$.

24. Metropolis N., Ulam S. The Monte Carlo method. Journal of the American statistical association. 1949. Vol. 44(247). pp. 335341.

25. Johansen A., Evers L. Monte Carlo methods. Lecture notes. University of Bristol, 2007. $128 \mathrm{p}$.

26. Halton J. H. A retrospective and prospective survey of the Monte Carlo method. Siam Review. 1970. Vol. 12(1). pp. 1-63. 国 